\title{
Organizational and Pedagogical Conditions of Academic Mobility Development of Students at School of Higher Professional Education
}

\author{
Elena E. Merzon ${ }^{1}$, Albina R. Fayzullina ${ }^{2}$, Rinat R. Ibatullin ${ }^{1}$, Dmitry A. Krylov ${ }^{3}$, Neile K. Schepkina ${ }^{4}$, Tatyana \\ V. Pavlushkina ${ }^{5}$ \& Elmira R. Khairullina ${ }^{6}$ \\ ${ }^{1}$ Yelabuga Institute of Kazan Federal University, Yelabuga, Russia \\ ${ }^{2}$ Kazan Federal University, Kazan, Russia \\ ${ }^{3}$ Mari State University, Yoshkar-Ola, Russia \\ ${ }^{4}$ Amur State University, Blagoveschensk, Russia \\ ${ }^{5}$ The Far East Higher Military Command College (the Military Institute), Blagoveschensk, Russia \\ ${ }^{6}$ Kazan National Research Technological University, Kazan, Russia \\ Correspondence: Elena E. Merzon, Director of Yelabuga Institute of Kazan Federal University, Kazanskaya \\ Street 89, Yelabuga, Tatarstan, 423600, Russia.
}

Received: October 24, 2014 Accepted: December 3, $2014 \quad$ Online Published: December 18, 2014

doi:10.5539/res.v7n1p46 URL: http://dx.doi.org/10.5539/res.v7n1p46

\begin{abstract}
The relevance of the stated problem is caused by the fact that the development of academic mobility of students and carrying out the program of mutual exchange and training of students and teachers in other higher educational institutions of Russia and the whole world, are one of the indicators of educational autonomy of the university. In this regard, this article reveals the conditions of formation, expansion, improvement of academic mobility of students, the conditions for a stable regulatory framework and the development of academic mobility conditions to prevent the brain drain. Proceedings of the article are of value to the heads of international departments and teachers of higher educational institutions of professional education, as well as valuable in the development of recommendations on the policy-making in the field of international education and the integration of the Russian professional schools into The Common Education Space.
\end{abstract}

Keywords: academic mobility, organizational and pedagogical conditions, improvement, development, formation, students of professional higher schools

\section{Introduction}

In modern conditions, the process of internationalization of public life promotes drastic reforms in the systems of professional education and training of competent specialists. Structural changes occur, the content of education, technology and teaching techniques are upgraded, there are new relations between professional education institutions and the labor market (Tregubova, 2009).

The best-known form of internationalization of professional education is an academic mobility of students, which is in the text of the Bologna Declaration characterized as one priority and, along with the task of ensuring the quality of education - as the main principle of creating The Common Education Space.

Promotion of mobility of students, the program of mutual exchange and training of students and teachers in other higher educational institutions of Russia and the whole world, is one of the indicators of educational autonomy of the university (Alder, 2006).

Academic mobility of contemporary students has an interdisciplinary content (Andreev, 2004), implies the willingness to change, the introduction of significant changes in their lives (Baydenko, 2010), correlates with advanced subjectivity as awareness of the importance of their own role in the success (Kiryakova et al., 2011), which is especially important in the formation aspect of a future competitive specialist (Schedrovitsky, 2007), where the social component plays an important role.

Academic Mobility is primarily an opportunity for students to organize their own educational path, within the educational standards to choose subjects, disciplines, courses, educational institutions in accordance with their 
aptitudes and aspirations (Znovenko \& Makarenya, 2005; Khairullina, 2007).

\section{Materials and Methods}

\subsection{Research Methods}

We have produced a sample of diagnostic techniques, allowing to adequately assess the level of development of certain personal qualities necessary for a student for the formation and development of academic mobility. Among these methods there are as follows: the procedure for evaluating the motivation for professional work, the procedure for evaluating the need for achievement, a technique to evaluate the ability to self-government in communication, the procedure for evaluating the professional activity communication, the procedure for evaluating human behavior in a real group, estimation technique of self-actualization, self-assessment methodology, the procedure for evaluating self-development and readiness for professional work.

\subsection{Criteria and Indicators}

We have found that mobility is not only seen as a process, but also as certain personality traits which appear only in activities. Based on the analysis of the structure and activity parameters of personal qualities necessary for the formation of academic mobility of students of a technical higher school, we have defined criteria and indicators for evaluation of the formation and development of academic mobility. These include:

- motivational criterion for assessing the motives of the individuals, encouraging activity on the formation and development of mobility (indicators: increase in the level of students' motivation for the academic mobility development, for designing their educational paths);

- organizing criterion to evaluate the ability of an individual to the organization of activities aimed at achieving certain goals (indicators: the ability to design one's own educational path; focus of the individual to continue his/her education, the development of self-education, flexibility and agility in setting educational goals and in achieving educational objectives);

- operational (the activity itself) criterion to evaluate the process and the result of the individual's activity on the formation and development of mobility (indicators: the student's movement (real and virtual) having vertical and horizontal directions; and the ability to self-realization and self-actualization);

- reflexive criterion to assess a person's ability to carry out reflection of his own activities on the formation and development of academic mobility (indicators: the ability to perform a reflection of one's activities).

This set of criteria, indicators and diagnostic methods was used both at the ascertaining stage of the experiment to assess the current level and capacity of students to develop mobility, and as well as after the forming experiment to measure progress or regression of students' willingness and commitment to the development of academic mobility.

\section{Results and Discussions}

\subsection{Groups of Organizational and Pedagogical Conditions of Academic Mobility Development}

As a result of studying the problem of the formation of academic mobility of students in higher schools we have subdivided 4 groups of conditions for its development in the domestic institutions of higher education:

\subsubsection{Terms of Expansion of Academic Mobility}

In the terms of expansion of academic mobility we include:

Preparation of university administrators and teachers for the role of the organizers of the process of academic mobility, the organization of exchanges between them within the framework of European programs to establish closer cooperation.

Development of multi-language, including study of relevant foreign languages even before the period of academic mobility; an internship in the part of language training, long-term retraining of teachers of a foreign language; development of common indicators to assess language proficiency of students and teachers; radical improvement in language training of students in general (Tregubova et al., 2008; Masalimova, 2008).

Creation of variants of the existing languages to facilitate communication in the social, technological and technical spheres of society. It is thus not about any artificial languages, but purposefully restricted natural languages, that is, the development of their simplified variants (such as Basic English, Grunddeutsch).

Facilitating access to information about academic mobility, including the creation of special sites on the major European resources and programs of academic mobility, the introduction of specialized forums at educational institutions (chat-rooms) for the organizers of the mobility of students, teachers, etc., to discuss and exchange 
information. Creation of a database in all bilateral and multilateral forms of programs of academic mobility in Europe. Creation of comparable statistics on academic mobility.

\subsubsection{Conditions to Create a Stable Regulatory Framework of Academic Mobility Development}

This group of conditions include a clear definition of the boundaries of the autonomy of universities in the Bologna process; variability in terms of instruction at the undergraduate and graduate levels in accordance with the European practice; determination of the status of "integrated Master" training programs; determination of the status of "professional" and "research" bachelors and masters; procedure for financing the training of masters; legalization of programs of academic mobility for Russian students and the order of set-off periods of study in other universities; development of quality control procedures provided by other university educational services, as well as the procedures for the recognition or rejection of inclusion in the individual study plan and a set of credits of courses of other universities; setting new standards of teaching load for teachers and hours for students' week teaching load.

\subsubsection{Terms of Improving Academic Mobility}

Terms of improving students' academic mobility include the following:

- increasing the number of members of academic mobility and its forms, in particular, the opening of summer universities for students and academic staff, distribution of training programs over the Internet, support for partnerships between universities about ensuring academic mobility;

- improvement and regularization of admission conditions for all groups of participants of academic mobility, including the provision of appropriate information in online mode;

- harmonization and simplification of the academic calendar of academic mobility on the basis of accurate and complete information on the activities of each university and feasible synchronization of university schedules, including exploration of possibilities to divide the school year into semesters with a corresponding admission (Aron, 2007; Odenbah, 2011);

- providing the necessary appropriate status for people involved in academic mobility, including measures such as an official confirmation by the relevant structures of the thesis that academic mobility is an essential component in the training of students as well as in professional and scientific training of the teaching staff of the University, up to exploring the possibility of incorporating the latter in science-teaching staff of the University for a period of mobility.

\subsubsection{Conditions Aimed at Preventing Brain Drain}

The problem of "brain drain" is not solved by a ban on international activities and contacts with foreign colleagues, but, vice-versa, through ordering such contacts and enabling the conditions for parallel research and teaching at home and abroad: to provide opportunities for teachers and researchers to participate in international conferences and colloquiums; allotment of special grants to teachers and researchers involved in the inter-institutional, cross-sector or international educational and research projects; giving the opportunities for employees to combine work in the home country with work abroad on a part-time basis; granting vacations to employees who leave to work or study abroad to add to the experience, with the reinstatement upon return (Marsland, 2006).

\subsection{Proceedings and Description of the Experiment}

The study of students' readiness for academic mobility formation at ascertaining stage of the experiment showed that the majority of the subjects of the studied group have enough potential for the academic mobility development: a sufficiently high level of readiness and desire for self-development, self-actualization and self-education; activity of future professionals, motivated by the content of engineering activities; clarity of goals, motivation to achieve success in the professional field; adequate self-esteem; awareness of personal and social significance of continuing education in engineering.

Thus, our diagnostic study confirms our assumption that the acquisition of only international educational experience by an individual is not a basis for the successful development of academic mobility. Future technical specialists must be prepared to design, implementation, reflection and change of their educational and professional reality in accordance with the objective circumstances.

For the design of their professional activities students were asked to study the implementation experience of the educational paths by Russian higher education students and by other countries' higher schools students, to choose their own educational path for modeling and develop a mechanism for the implementation of the elected path. 
This research was conducted on the selected criteria and indicators. To present the results of the comparative analysis of the two stages of the experiment - the ascertaining and after forming - we have made a selection of some diagnostic techniques we used. The results of the repeated diagnosis analysis are listed in Table 1.

Table 1. Comparative analysis of the key indicators of the levels of students' academic mobility formation at the ascertaining and formative stages of the experiment

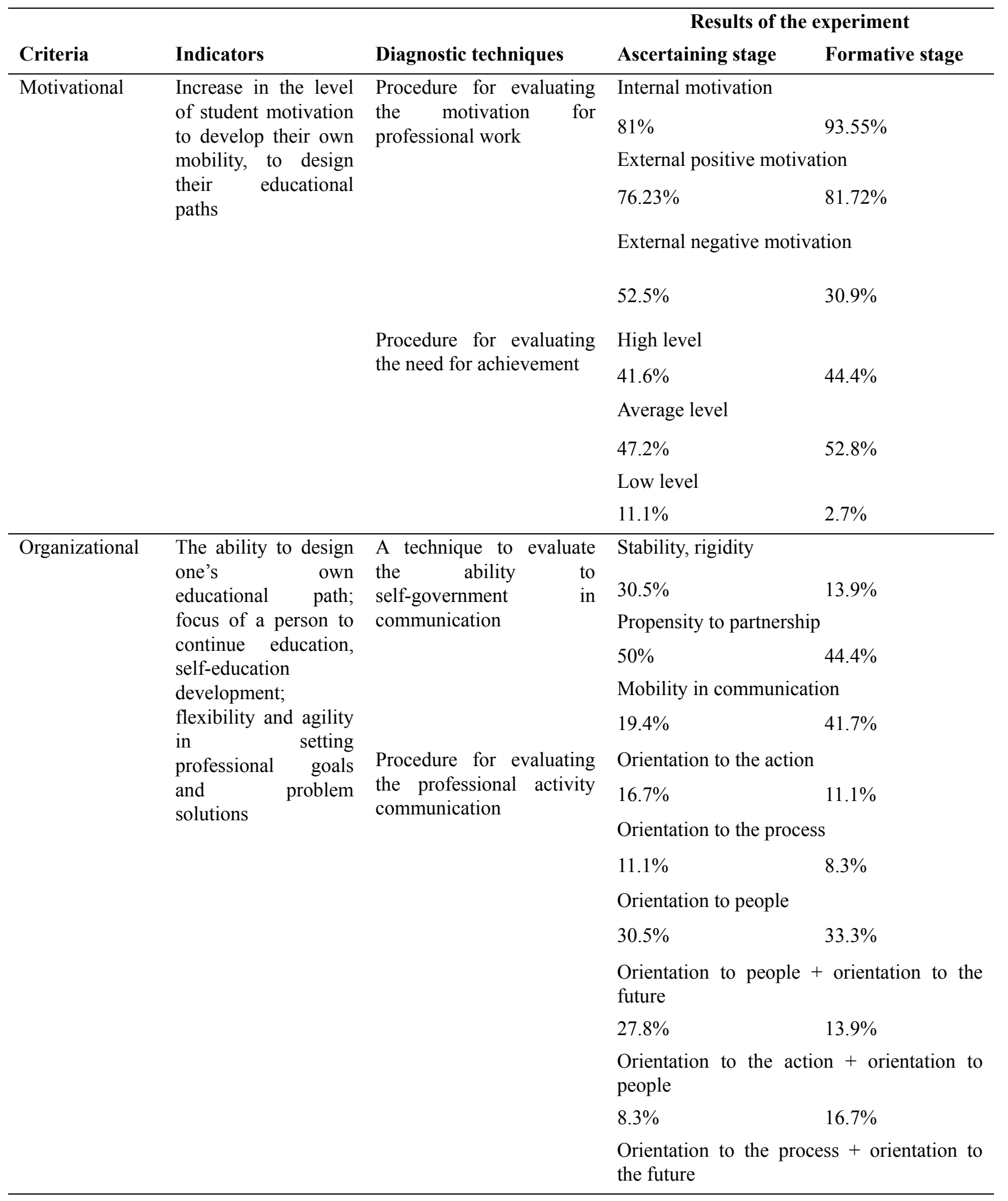




\section{$5.5 \% \quad 16.7 \%$}

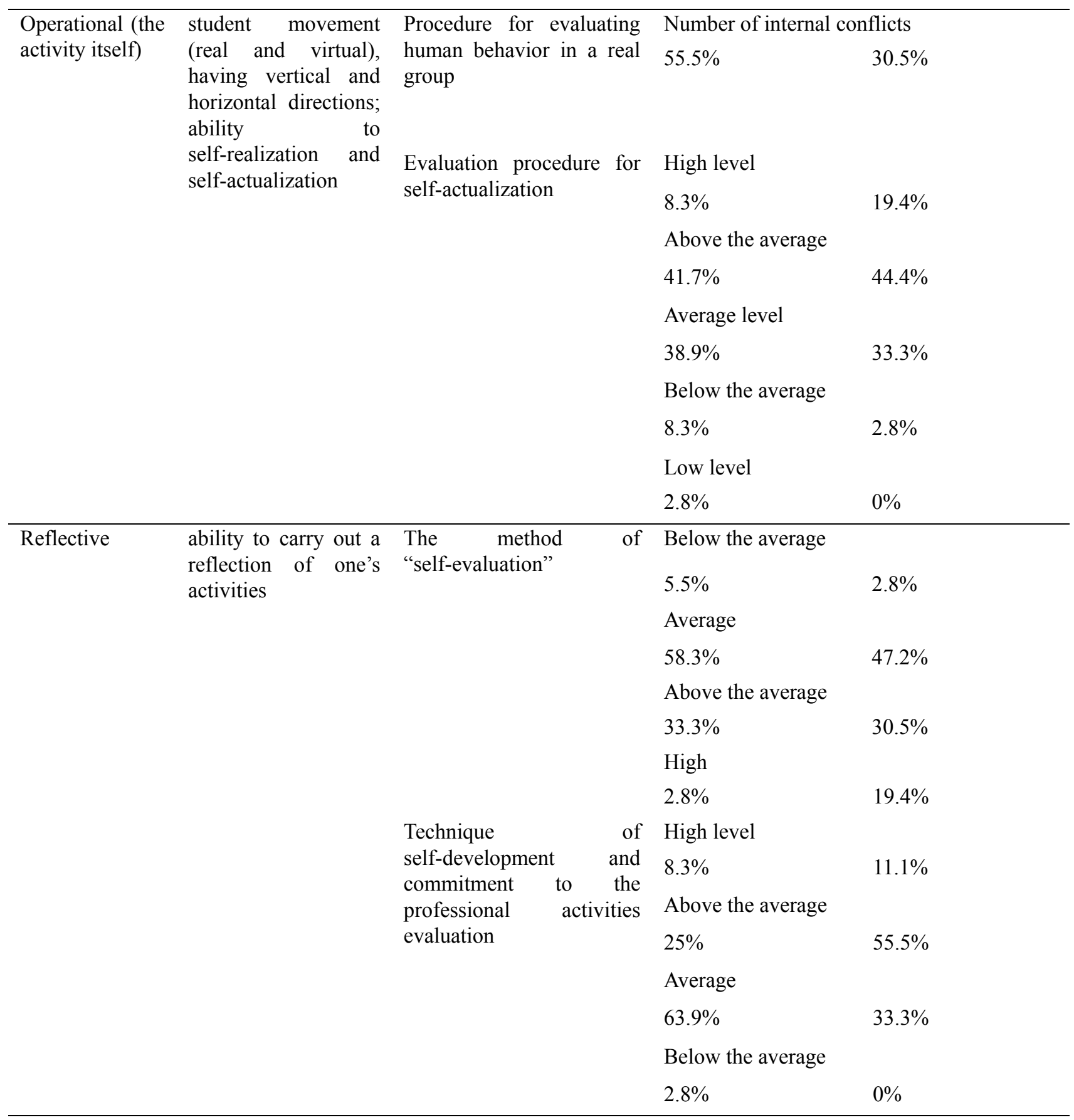

Experimental work on the formation of academic mobility of students has shown that the development of individual and personal component of the system of continuing professional education, the designing of professional activities allow the students to better assess their own capabilities in the selected educational and professional sphere of activity, to predict the possible ways of development of professional activity. Furthermore, as the data of repeated diagnosis have shown, the conducted experimental work contributes to the development of such qualities of a student as the desire for self-actualization, self-development and self-realization, reasonable self-esteem of personal and professional qualities, which, in turn, contribute to the formation and development of the student's academic mobility.

\section{Conclusion}

Thus, organizational and pedagogical conditions of formation, expansion, improvement of academic mobility of 
students, the conditions for a stable regulatory framework of the academic mobility development and the conditions to prevent the problem of "brain drain" presented in the article lead to the conclusion that only the international educational experience acquisition by a person is not a basis for the successful development of academic mobility. Academically mobile and competitive future professionals should be prepared for the designing, implementation, reflection and changing of their educational and professional reality in accordance with the objective circumstances.

\section{Acknowledgments}

The authors thank all participants of this study for their kind cooperation.

\section{References}

Alder, T. A., Podaneva, T. V., \& Orlova, E. A. (2006). Subjective aspect of the modernization of higher education. Science and education. Proceedings of the VI Intern. scientific. Conf, Belov branch KemSU.

Andreev, V. I. (2004). Konkurentologiya: Training course for creative self-development competitiveness. Kazan.

Aron, R. (2007). Main currents in educational thought. Middlesex: Penguin Books.

Baydenko, V. I. (2010). The main trends in the development of higher education: Global and Bologna measurement (p. 352). Moscow Research Center of the quality of training MISA.

Khairullina, E. R. (2007). Orientation of students to self-development of core competencies in the design and creative activity. Science and Education Journal, 7.

Kiryakova, A. V., Mosienko L. V., \& Olkhovaya, T. A. (2011). Axiological markers of education quality in the Bologna process context. Fundamental Researches, 8, 519-523.

Marsland, D. (2006). Education and Youth. The Fallmer Press.

Masalimova, A. R. (2008). Formation of academic mobility of students of higher technical school abroad: Ideas, principles, performance criteria. Engineering Pedagogy, 9, 239-243.

Odenbah, I. A. (2011). Leveled performance indicators for Mobility students. Education, Science, Brainpower: quarterly journal, 2,158-161.

Schedrovitsky, G. P. (2007). Lectures on pedagogy (p. 400). Moscow.

Tregubova, T. M., Sakhiev, R. G., Masalimova, A. R., Rafikova, E. M., Beljakin, A. M., Fakhrutdinova, A. V., \& Tazutdinova, E. H. (2008). Academic mobility of students as a factor in the preparation of a competitive specialist in the context of the Bologna process. Kazan: Danis PPIs RAO.

Tregubova, T. M. (2009). Formation of academic mobility of students of vocational schools in the face of international educational integration. Vocational education in Russia and abroad, 1(1), 35-39.

Znovenko, L. V., \& Makarenya, A. A. (2005). Academic mobility of students as a factor in the successful establishment of professional competence of future teachers (pp. 105-109). Petersburg: GNU RMAs RAO.

\section{Copyrights}

Copyright for this article is retained by the author(s), with first publication rights granted to the journal.

This is an open-access article distributed under the terms and conditions of the Creative Commons Attribution license (http://creativecommons.org/licenses/by/3.0/). 